\section{Em Busca de Cidades Ativas: a Prática da Corrida como Mobilidade Urbana}

\author{
Seeking for Active Cities: the Practice of Running as Urban \\ Mobility
}

\section{RESUMO}

O presente artigo objetiva trazer uma abordagem reflexiva sobre meios de tornar nossas cidades mais ativas a partir do movimento Cidade Ativa, com enfoque na promoção da corrida como meio de deslocamento incentivado pela iniciativa Corridaamiga. Cidade Ativa é uma organização social criada para fomentar a discussão sobre os impactos que o planejamento urbano e a arquitetura das edificações exercem sobre os estilos de vida e a saúde pública. Corridaamiga é uma iniciativa que fomenta o transporte ativo por meio da corrida que surgiu no início de 2014, fruto da ação de corredores de rua que gostariam de auxiliar e inspirar a prática da corrida como forma de mobilidade urbana. Especialistas de diversos países estão começando a discutir e reconhecer o papel de "transporte ativo" como uma alternativa ao estilo de vida sedentário e como uma forma de melhorar a qualidade de vida da população. Assim, a união do Cidade Ativa com a Corridaamiga busca dialogar sobre oportunidades de transformações nas cidades que incentivem um estilo de vida mais ativo e saudável aos cidadãos. O presente artigo aponta os primeiros resultados, bem como os desafios e as perspectivas dessa iniciativa.

Palavras-chave: Cidade Ativa. Corridaamiga. Deslocamento Ativo. Mobilidade Urbana. Cidades.

\section{ABSTRACT}

This paper aims to bring a reflective approach regarding opportunities of encouraging physical activity and healthy lifestyles in cities, through the Cidade Ativa perspective, focusing on the promotion of run commuting, supported by the initiative Corridaamiga. Cidade Ativa aims to explore the impact that urban design and architecture have on people's lifestyles and public health. Corridaamiga is an initiative that aims to foster the active transportation though running which emerged in early 2014 as a
Silvia Regina Stuchi Cruz

Universidade de Campinas. Instituto de Geociências, São Paulo, Brasil

Anna Gabriela

Hoverter Callejas

Columbia University. Graduate School of Architecture Planning and Preservation, Nova York, Estados Unidos

\section{Mariana Santos}

Universidade de São Paulo. Escola Politécnica, São Paulo, Brasil 
result of the "Brazilian run commuters" action that assists and inspires the practice of running as urban mobility. Experts worldwide are beginning to discuss and recognize the role of "active transportation" as an alternative to the sedentary lifestyle and as a way to improve the quality of life of the population. Thus, the combination of Cidade Ativa and Corridaamiga aims to dialogue about opportunities for transforming cities in order to encourage a more active and healthier lifestyle, identifying first results as well as challenges and opportunities.

Keywords: Active Cities. Friendly Running. Active transportation. Urban mobility. Cities.

\section{INTRODUÇÃO}

O tema "mobilidade urbana" vem ganhando destaque nas discussões sobre desenvolvimento/planejamento urbano no Brasil ao longo dos últimos anos por diversos motivos: aumentou-se o grau de urbanização, elevou-se o número da população e, sobretudo, houve aumento significativo no número de veículos automotores nas ruas dos grandes centros urbanos, ou seja, por conta dos congestionamentos, o tempo gasto nos deslocamentos também acompanhou esse aumento [4].

De acordo com o Instituto de Pesquisa Econômica Aplicada (IPEA) [14], chegar ao trabalho custa mais tempo nas regiões metropolitanas de São Paulo e Rio de Janeiro do que em Londres, Nova York, Tóquio, Paris e várias outras grandes cidades. $\mathrm{O}$ tempo despendido no trânsito vem piorando consideravelmente ao longo das últimas décadas, tanto pela carência de transporte público, quanto pelo aumento da frota de veículos, que congestionam as vias públicas. $\mathrm{O}$ tempo de deslocamento gasto está diretamente associado ao bem-estar e qualidade de vida dos indivíduos, uma vez que, ao se perder mais tempo nos deslocamentos diários, diminui-se o tempo para práticas esportivas e lazer [1, 27, 32].

Assim, em uma escala inversa, aumenta-se o número de doenças e complicações diretamente relacionadas ao sedentarismo e obesidade. O número de brasileiros mortos por complicações diretamente relacionadas à obesidade triplicou em um período de dez anos [6]. Outro tema ligado à questão de saúde pública é o aumento da poluição devido à queima de combustíveis fósseis pelos automóveis. Somente na cidade de São Paulo, cerca de quatro mil pessoas morrem anualmente em consequência de problemas causados pela poluição do ar [28].

Estudos relacionados ao tema "deslocamento ativo" vêm crescendo mundialmente, pois o sedentarismo está intimamente ligado a problemas de saúde pública, como obesidade, diabetes e problemas de saúde relacionados à poluição atmosférica. Assim, medidas visando potencializar a prática do deslocamento ativo podem contribuir positivamente em áreas como meio ambiente, transporte e saúde da população. Logo, o tema deve ser analisado com atenção pelas entidades públicas, privadas e pela própria sociedade.

Deste modo, o presente artigo objetiva trazer uma abordagem reflexiva sobre meios de tornar nossas cidades mais ativas a partir do movimento Active Design [24], com enfoque na promoção da corrida como meio de deslocamento, fomentado pela iniciativa Corridaamiga, apontando os primeiros resultados, bem como os desafios e perspectivas. 
A união desses dois grupos busca dialogar sobre oportunidades de transformações nas cidades que incentivem um estilo de vida mais ativo e saudável aos cidadãos.

\section{CIDADE ATIVA}

Sabe-se que a qualidade de vida de indivíduos está intimamente ligada ao meio em que vivem. A tendência de concentração de populações nos centros urbanos coloca o planejamento das cidades como epicentro dos estudos sobre hábitos, estilo de vida e, portanto, como centro de estudos e debates sobre saúde pública. A forma de edifícios - sejam estes residências, locais de trabalho, escolas, centros de comércio e serviços, etc. -, a estrutura de bairros, a qualidade dos espaços públicos e os sistemas de mobilidade influenciam diretamente sobre escolhas e comportamentos de indivíduos.

No Brasil, a rápida urbanização e o gradual aumento da qualidade de vida e do nível econômico dos brasileiros trouxe uma importante mudança no quadro da saúde: o país tem seguido a tendência de países desenvolvidos e passou a enfrentar doenças causadas pela mudança de estilo de vida e hábitos alimentares de seus cidadãos. Se antes as doenças infecciosas eram responsáveis pela maioria dos óbitos no país, hoje as doenças não transmissíveis (que incluem doenças crônicas como cânceres, doenças cardiovasculares, etc.) são responsáveis por 74\% das mortes dos brasileiros [33].

Muitas dessas doenças estão ligadas à obesidade, ao sedentarismo e à diabetes doenças causadas ou agravadas por um estilo de vida pouco ativo e por maus hábitos alimentares -, que podem ser reunidas em uma nova categoria, a de "doenças de desequilíbrio energético". Dados do Ministério da Saúde de [20] mostram que 11,7\% da população é diagnosticada com diabetes e em torno de $24,3 \%$ dos adultos sofre de hipertensão. Além disso, é preocupante o aumento de obesos e de pessoas acima do peso: $50.6 \%$ têm excesso de peso* e $17.2 \%$ é considerada obesa**.

Nossa genética não mudou em uma geração, mas o ambiente em que vivemos, sim. No século XIX e XX as doenças infecciosas foram combatidas por reformas urbanas que garantiam infraestrutura de saneamento, maior ventilação e insolação de edifícios; acredita-se, portanto, que as doenças de desequilíbrio energético do século XXI podem também ser prevenidas e controladas por um novo modelo de planejamento, de desenho urbano e arquitetura que sigam as estratégias discutidas pelo movimento Active Design [25].

Active Design é um movimento iniciado nos Estados Unidos que pretende promover hábitos saudáveis e estilo de vida ativo a partir do desenho de edifícios, de cidades e de políticas públicas nas áreas de planejamento, construção e saúde. As diretrizes defendidas pelo Active Design foram consagradas através da publicação do Active Design Guidelines, desenvolvido pelos departamentos de planejamento, de construção, de transporte e de saúde da cidade de Nova Iorque - e de outros estudos que o precederam. Em conjunto com o American Institute of Architects (AIA) e com governos

*Índice de Massa Corpórea (IMC) acima de $25 \mathrm{~kg} / \mathrm{m}^{2}$.

** IMC acima de $30 \mathrm{~km} / \mathrm{m}^{2}$. 
locais de diversas cidades dos Estados Unidos, o movimento vem ganhando força nos últimos anos através de eventos anuais realizados sobre o tema. Desde 2011, o Active Design ganhou relevância mundial através dos encontros Fit World e passou a reunir profissionais de todo o mundo em iniciativas que propõem uma nova maneira de pensar cidades e a saúde de seus cidadãos.

Cidade Ativa é uma organização social criada para fomentar a discussão sobre o impacto que o planejamento urbano e a arquitetura das edificações exercem sobre estilos de vida e sobre saúde pública e utiliza o movimento Active Design como uma de suas principais referências para a proposta de formulação, em conjunto com diversos atores, do conceito "cidade ativa". A organização atua em torno de três ações principais:

1. Mobilização através da organização de palestras*** ${ }^{*}$ oficinas, criação de campanhas educativas, divulgação de projetos e pesquisas relacionadas ao tema e coordenação da plataforma Grupo de Trabalho Fit Cities, que reúne múltiplos atores ${ }^{* * * *}$;

2. Execução de projetos e realização de pesquisa em parceria com outras instituições;

3. Consultoria para organizações que queiram incorporar novas diretrizes para promoção de estilo de vida ativo em projetos de arquitetura e urbanismo, na elaboração de novos processos internos que promovam mudança de comportamento de funcionários e colaboradores e no desenvolvimento de políticas públicas.

\section{Promovendo Deslocamento Ativo}

Novas políticas de uso do solo, densidade habitacional, mobilidade, planejamento de espaços livres para recreação e prática de esportes e acesso à alimentação saudável, entre outras, podem ajudar a transformar o ambiente urbano e a promover mudança de hábitos na população [25]. O surto de urbanização das grandes cidades brasileiras acabou por privilegiar o transporte individual; houve a proliferação de condomínios fechados e bairros de baixa densidade, murados e distantes dos centros de trabalho, comércio e serviços, que gerou um descaso em relação à criação de parques, praças e áreas de recreação e à manutenção de espaços públicos.

A combinação destes e de outros fatores é responsável pela crise de mobilidade que está sendo enfrentada pelos grandes centros urbanos do país. A insuficiência e ineficácia das redes de transporte público existentes e a escassez de infraestrutura de calçadas e

\footnotetext{
${ }^{* * \star}$ Dentre as atividades realizadas pelo Cidade Ativa, destaca-se o primeiro Seminário Internacional Fit Cities, organizado em conjunto com o grupo USP Cidades, na Cidade Universitária, em abril de 2014, e a oficina Safári Urbano, registrada pela equipe de reportagem da USP e disponível para visualização através do site <http://www5.usp.br/42627/safari-urbano-avalia-conforto-e-saude-dos-pedestres-em-sao-paulo/>.

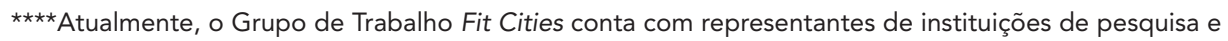
ensino (incluindo USP Cidades, Faculdade de Saúde Pública da USP e CEPEUSP), de empresas privadas, organizações sociais e indivíduos.
} 
ciclovias estimulam o uso de veículos privados para deslocamentos diários, escolha também incentivada por políticas de subsídios à indústria automobilística a nível nacional.

Uma das estratégias principais do Cidade Ativa é o incentivo ao deslocamento ativo, que consiste em meios de transporte baseados na força do corpo humano [17], como caminhada, uso de bicicleta, cadeira de rodas, skate, patins e similares. As horas de trabalho, somadas às horas de deslocamento diário das populações em grandes cidades reduz o tempo de lazer de indivíduos, que poderia ser dedicado à prática de atividade física. Neste sentido, aposta-se na prática de deslocamento ativo como uma das maneiras de combate ao sedentarismo. Estudo realizado em São Paulo em 2007, no distrito de Ermelino Matarazzo, mostrou que enquanto $68,7 \%$ da população adulta não praticava exercício no tempo de lazer, $85,7 \%$ praticava a caminhada como forma de transporte para deslocamentos com duração acima de 10 minutos por semana, sendo que $35,4 \%$ dos entrevistados disseram caminhar durante 150 minutos ou mais por semana [7].

Sabe-se que este padrão de deslocamento é recorrente principalmente em zonas com baixo nível socioeconômico [26], distantes do centro e com usos do solo predominantemente residenciais, mas a prática de atividade física através de deslocamentos ativos mostra-se como realidade para uma grande parte da cidade de São Paulo, e pode servir como exemplo para outras regiões.

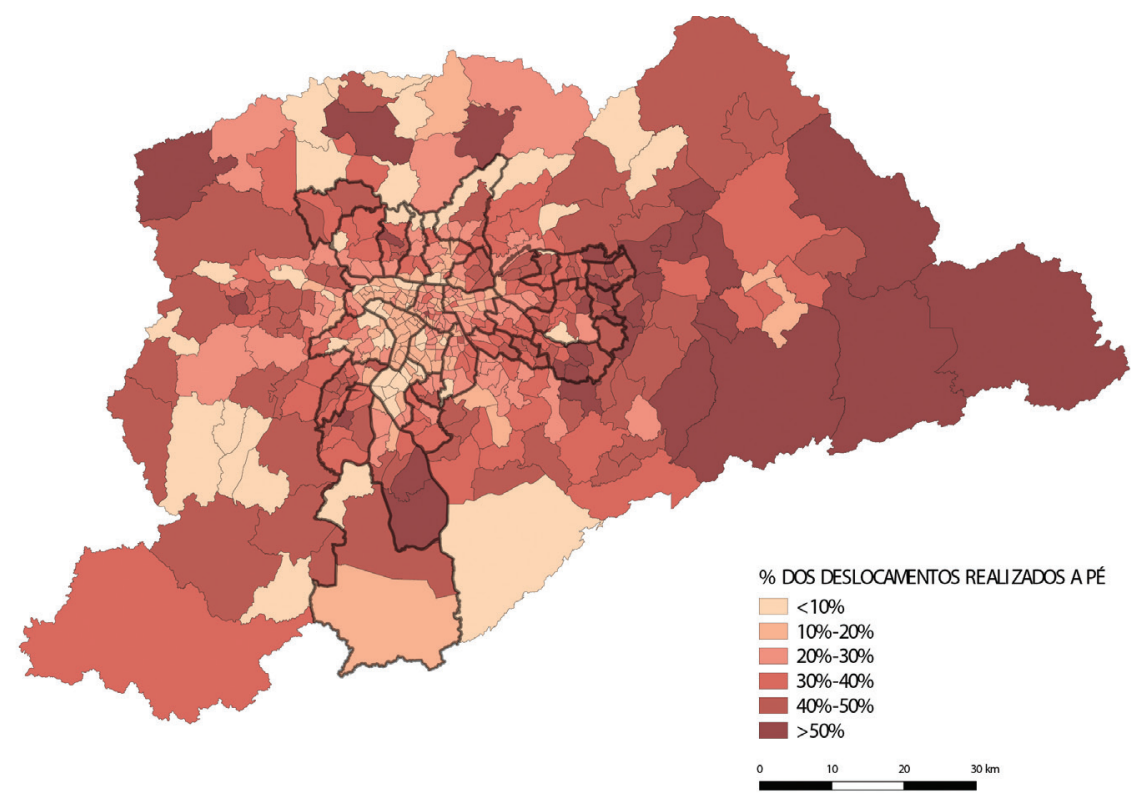

A aprovação do novo Plano Diretor Estratégico para a cidade de São Paulo gera uma grande expectativa em relação a uma possível mudança dos padrões de deslocamento da população: um dos seus objetivos é a redução da necessidade e dos tempos de deslocamento através de uma nova política de uso do solo que permita a aproximação dos locais de trabalho aos locais de moradia [31]. Baseada em conceitos
Figura 1 - Porcentagem de deslocamentos feitos a pé, por zona de origem. Figura elaborada por Anna G. H. Callejas a partir de dados da Pesquisa Origem e Destino 2007 [26]. 
já amplamente aplicados em cidades europeias e dos Estados Unidos, essa nova estratégia para a cidade de São Paulo poderá:

") acarretar na descentralização dos locais de trabalho, incentivando a formação de novas centralidades em áreas que atualmente possuem alta densidade populacional;

" propiciar a construção de moradias em áreas centrais da cidade e próximas aos centros de trabalho existentes;

" incentivar a construção de moradia e trabalho ao longo dos eixos de transporte de média e alta capacidade, incentivando o uso do transporte público e, portanto, das formas de deslocamento ativo associadas ao seu uso;

" desincentivar a construção de estacionamentos.

Esta nova visão para a cidade, defendida através da revisão de marco regulatório em curso, traz consigo a necessidade de construção de infraestrutura de transporte que permita formas de deslocamento compatíveis com esse modelo de cidade. Além da necessidade evidente de aumento de investimento no transporte público, as infraestruturas para deslocamento a pé e bicicleta terão que ser reformadas ou totalmente implantadas em alguns casos. Essa política enfrentará desafios que vão desde a revisão de leis complementares (que ditam, por exemplo, sobre a responsabilidade de construção e manutenção de calçadas), à discussão sobre destinação de recursos públicos, educação no trânsito e reações adversas por parte da população, já que tal política exige uma mudança drástica de comportamento.

É neste contexto que ações como as desenvolvidas pelo Cidade Ativa e pela Corridaamiga se fazem essenciais, podendo atuar na reivindicação de políticas, projetos e processos que estimulem a prática de deslocamento ativos nas cidades ou que garantam que a totalidade da população possa optar por se deslocar desta maneira, além de contribuir para a divulgação de iniciativas e conscientização da população para o tema do deslocamento ativo e os seus benefícios na saúde.

\section{A Prática da Corrida como Forma de Mobilidade Urbana}

Na Europa e nos Estados Unidos, a prática da corrida como meio de transporte já está difundida, denominada de run commuting***** . No Brasil, essa atividade ainda encontra-se em fase embrionária, logo, é indispensável atuar na divulgação dessa modalidade de deslocamento, bem como nos entraves que ainda dificultam realizar a corrida como uma opção viável e saudável de transporte para os indivíduos.

Há dados que demonstram a difusão da prática, como, por exemplo, o aumento significativo no número de corredores no Brasil; segundo dados da Corpore [5], a

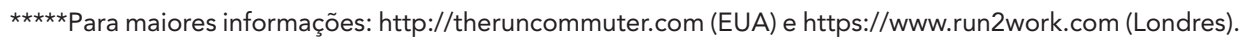


organização conta com 430 mil corredores cadastrados. Além disso, a cultura da corrida é essencialmente urbana, hipótese comprovada pelos dados da pesquisa DNA do corredor [13], mostrando que $47 \%$ dos corredores treinam nas ruas.

\section{Corridaamiga}

A prática da corrida como meio de transporte é indicada para distâncias de até $10 \mathrm{~km}$, o que supõe um raio relativamente pequeno da cidade, mas que, por outro lado, são áreas que concentram grandes focos de trânsito. De acordo com o estudo da Companhia de Engenharia de Tráfego (CET) [4], aponta-se que 35\% dos ônibus trafegam em todas as vias da cidade de São Paulo com velocidade abaixo de $15 \mathrm{~km} / \mathrm{h}$. O mesmo relatório mostra que houve queda considerável nas velocidades médias (centro-bairro/bairro-centro) de 2008 para 2012: 20,6 km/h em 2008 e 18,4 km/h em 2012 (queda de 10,7\%); já para o pico da tarde no sentido bairro (CB), a velocidade era de $18,6 \mathrm{~km} / \mathrm{h}$ em 2008 e passou para $15,3 \mathrm{~km} / \mathrm{h}$ em 2012 (queda de 17,7\%). Em contrapartida, a velocidade média de um corredor de rua amador é cerca de $10 \mathrm{~km} / \mathrm{h}[3]$.

De acordo com a pesquisa DNA do corredor [13], 95\% dos praticantes de corrida influenciam e motivam a prática da corrida, ou seja, o perfil dos praticantes é considerado influenciador e motivador. Nesse contexto, a Corridaamiga é um novo conceito de locomoção, o transporte ativo compartilhado, que surgiu no início de 2014 fruto da iniciativa de corredores de rua já acostumados a se deslocarem pela cidade utilizando seus pés, e que gostariam de auxiliar e inspirar a prática da corrida como forma de mobilidade urbana.

Há duas formas principais de participação: pedindo uma Corridaamiga ou sendo um corredor amigo. O cadastro deve ser realizado na plataforma online da Corridaamiga ${ }^{* * * * *}$. Após o recebimento dos cadastros, há o cruzamento de percursos das pessoas, ou seja, os corredores amigos mais próximos ao pedido de Corridaamiga realizam o trajeto em conjunto e/ou fornecem, voluntariamente, instruções e informações aos iniciantes no uso da corrida como meio de transporte sobre as melhores rotas, como correr na rua, o uso das calçadas, o respeito ao pedestre, a logística de roupas, equipamentos e itens indispensáveis para o uso da corrida como meio de deslocamento.

\section{MÉTODOS}

A iniciativa Corridaamiga é realizada através de página na internet e nas redes sociais. Os atendimentos de Corridaamiga são realizados da seguinte maneira: após o preenchimento dos pedidos no site, cruzamos os dados com o corredor voluntário mais próximo da região solicitada. Caso não existam voluntários atuando no referido local, auxiliamos com troca de informações, respondendo dúvidas, sugerindo rotas, entre outros procedimentos. Assim, o intuito principal do projeto é levar a outros cidadãos todos os benefícios atrelados à prática da corrida como mobilidade urbana.

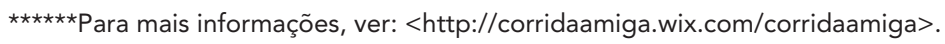




\section{Ações Desenvolvidas}

Os principais impactos do projeto na comunidade obtidos até o momento são:

\section{Construção do website}

O site da Corridaamiga é destinado ao desenvolvimento e promoção da prática da corrida como meio de deslocamento, com a inserção de dados e informações disponibilizados por colaboradores (corredores da rede Corridaamiga) e coletados em outras fontes secundárias (bibliografia e sites especializados em corridas).

\section{Atendimentos de Corridaamiga}

Até outubro de 2014, o grupo atendeu 59 pedidos de Corridaamiga, em sua maioria nos grandes focos de trânsito da cidade de São Paulo. Atualmente, a rede conta com 53 corredores voluntários de São Paulo-SP e outras cidades, como Campinas, Mogi das Cruzes, São Bernardo do Campo e Santo André, além de estados como Paraná, Santa Catarina, Rio Grande do Sul, Rio de Janeiro, Rio Grande do Norte, Bahia e Ceará.

Figura 2 - Pedidos de Corridaamiga e corredores voluntários pelo Brasil. Fonte: Corridaamiga

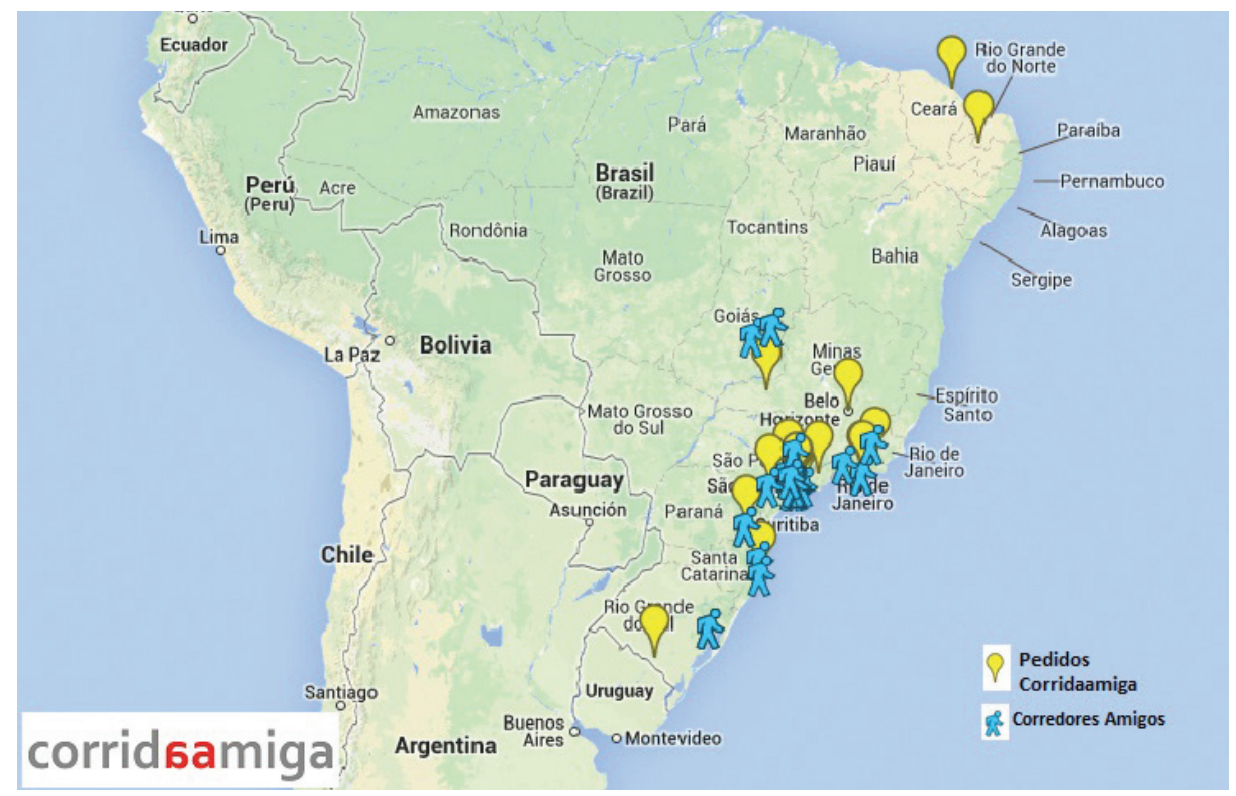

Assim, sobretudo por conta da demanda e interesse em encontrar soluções para fugir do caos do trânsito, a tendência é a de um crescimento da rede de corredores amigos. 


\section{Realização de trabalhos de divulgação em mídias sociais e elaboração de material}

As ações desenvolvidas foram conduzidas pela produção de material gráfico para divulgação da corrida como meio de transporte, tais como folders e adesivos.
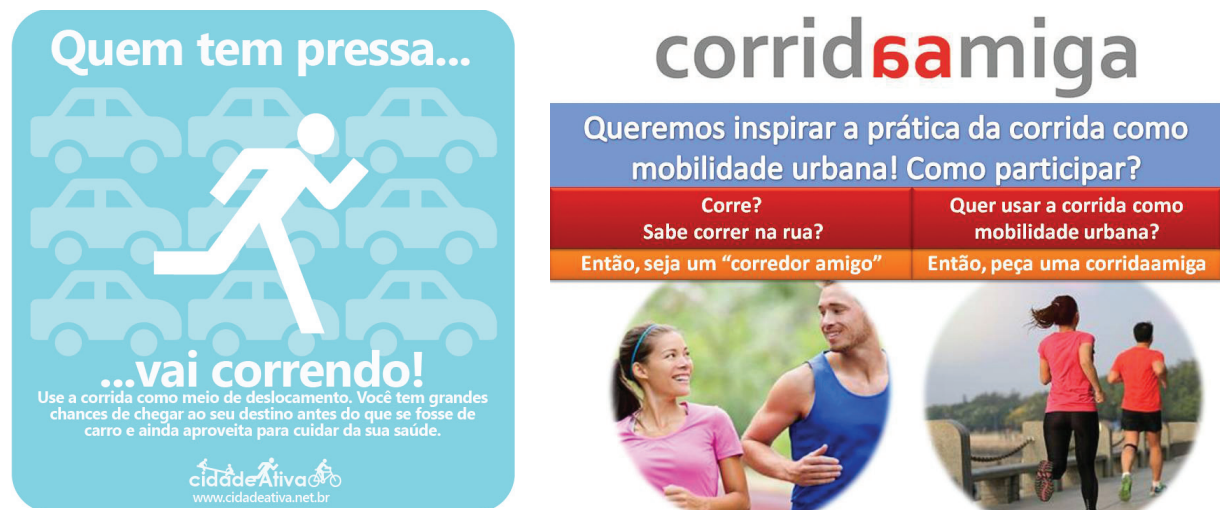

\section{Organização do Dia de Correr para o Trabalho no Brasil}

Organização do Dia de Correr para o Trabalho visou à divulgação da modalidade de deslocamento, bem como os entraves que ainda dificultam realizar a corrida como uma opção viável e saudável de transporte para os indivíduos. Vários grupos e organizações apoiaram as ações realizadas pela Corridaamiga, tais como: Mobilize [22], GreenPeace [10], Cidadera, Cidade Ativa, Jornal Corrida [15] e Bike Anjo.

As condições inadequadas das nossas calçadas dificultam o uso da corrida como meio de transporte, assim como a mobilidade de idosos, crianças e deficientes. Nesse sentido, salientando a preocupação com as calçadas que encontramos diariamente na cidade, as pessoas foram convidadas a postar seus selfies com alguma inadequação encontrada na calçada incluindo o hashtag \#calçadacilada.

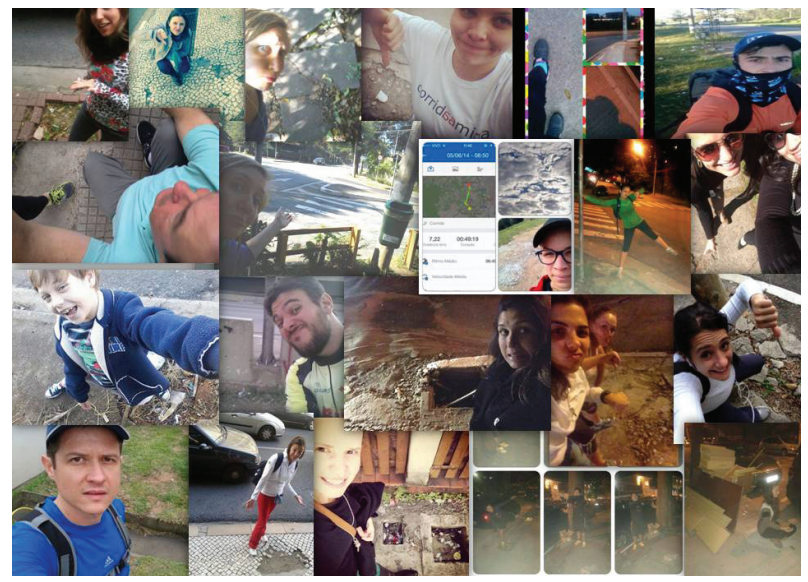

Figura 4 - Montagem de selfies da campanha \#calçadacilada. Fonte: Corridaamiga 
Até o momento, os desafios e entraves que ainda dificultam a realização da corrida como uma opção viável e saudável de transporte para os indivíduos relacionam-se sobretudo ao estado de nossas calçadas, à falta de segurança e à indisponibilidade de vestiários e chuveiros por parte das empresas/universidades.

\section{Calçadas}

De acordo com ANTP [2], "pedestres são o elo mais frágil da cadeia de mobilidade urbana, especialmente idosos, crianças e pessoas com alguma restrição física”. O estado de nossas calçadas é um dos principais motivos que barram o deslocamento dos pedestres, sendo também um entrave para a prática de corrida de rua. Segundo o IBGE [11], um terço das viagens urbanas diárias são feitas a pé, em geral pequenos trajetos até a escola, creche, mercado, mas também viagens longas, de vários quilômetros até o local de trabalho. Porém, nos últimos anos, calçadas foram reduzidas ou, em alguns casos, eliminadas para dar espaços a mais vias na tentativa de melhorar o tráfego de veículos [21].

Em 2012, uma campanha realizada pela organização não governamental Mobilize Brasil constatou que a nota média dada aos calçamentos em 39 cidades do país, entre elas a cidade de São Paulo, não passava de 3,5 [21]. Além disso, a entidade aponta que $90 \%$ dos sinais de trânsito são direcionados aos motoristas, embora dois terços das viagens urbanas diárias sejam feitas a pé [22, 23].

\section{Falta de segurança}

Estudos epidemiológicos mostram que a prática de atividade física, tanto para fins de lazer como deslocamento, está associada à percepção de acessibilidade, conveniência, facilidade, segurança geral (incluindo segurança no tráfego e no ambiente) e apoio social $[7,8,29,30]$.

\section{Indisponibilidade de vestiários e chuveiros}

A instalação de vestiários com chuveiros faria com que os cidadãos se sentissem mais motivados a realizar seus trajetos correndo. Esse é um grande entrave apontado pelos praticantes da modalidade para que a prática seja disseminada.

\section{Distância}

Outro grande desafio é a distância entre os locais de trabalho/escola e os locais de moradia - a distância que tem que ser vencida por deslocamentos na cidade de São Paulo, que caracteriza o movimento "pendular" do centro à periferia. Com longas distâncias, correr acaba não sendo uma opção. Por isso a necessidade de desenvolvimento de uma cidade compacta defendida pelo novo Plano Diretor Estratégico para São Paulo [31]. No entanto, sugere-se que, se o trajeto a ser realizado for maior do que 
$10 \mathrm{~km}$, seja utilizado transporte público até determinado local e o início da corrida se dê a partir desse ponto ou, ainda, estacionar o carro em um local mais distante do trabalho e ir/voltar correndo.

\section{CONSIDERAÇÕES FINAIS}

A comparação da velocidade média de um veículo automotor no horário de pico ( 15 $\mathrm{km} / \mathrm{h}$ ) e de um corredor de rua amador ( $10 \mathrm{~km} / \mathrm{h}$ ) são dados que assustam e nos fazem repensar o nosso modo de vida e a deficiência de planejamento da nossa cidade, caracterizando um espaço público mal concebido e pouco aproveitado que não favorece o convívio e a interação social.

Atualmente não é possível dissociar mobilidade urbana de assuntos tais como planejamento urbano, habitação, meio ambiente, saúde e desenvolvimento econômico. Entre 2009 e 2012, segundo a Pesquisa Nacional por Amostragem de Domicílios [12], houve aumento de $37 \%$ para $42,4 \%$ das famílias com pelo menos um carro. Segundo a ANTP, a frota de carros no país cresceu 105\% entre 2002 e 2012. Dados da recém-divulgada Pesquisa de Mobilidade realizada pelo Metrô de São Paulo mostram que em uma comparação entre 2007 e 2012 houve uma redução no uso de transporte coletivo pelas pessoas de menor renda (queda de $2 \%$ na faixa até R $\$ 2.448$ e de $4 \%$ na faixa de $\mathrm{R} \$ 1.248$ a R\$ 4.976) ante um aumento no uso de transporte público em segmentos de maior renda ( $1 \%$ na faixa de $\mathrm{R} \$ 4.976$ a $\mathrm{R} \$ 9.330$ e de $6 \%$ na faixa acima de $\mathrm{R} \$ 9.330$ ). Ainda com pequena participação no quadro geral, os deslocamentos de bicicleta e a pé também cresceram no período de 2007 a 2012: 7\% e 9\%, respectivamente [18].

No Brasil, apesar da ausência de dados específicos relacionados à corrida como meio de transporte, mundialmente nota-se uma tendência à utilização da corrida e caminhada como meio de transporte, tendo em vista o tempo de viagem, riscos e efeitos à saúde causados pelo uso de transporte individual ou coletivo motorizado em grandes cidades. Alguns artigos já apontam a correlação destes fatores. Um estudo recente, liderado pelo Dr. Christopher Millett do Imperial College London [19], revelou que na Índia metade das pessoas que se deslocam para o trabalho utilizando veículo próprio estão acima do peso em comparação às pessoas que se deslocam para o trabalho por meio de caminhada ou uso de bicicleta. Além disso, o estudo aponta a hipótese de que a mudança no meio de transporte para o trabalho pode ser responsável pela redução de risco às doenças tais como diabetes, pressão alta e doenças crônicas. Da mesma maneira, estudo realizado em 10 mil pessoas em Atlanta revelaram que cada quilômetro adicional caminhado diariamente está associado à redução de $4,8 \%$ no risco à obesidade, enquanto cada quilômetro de deslocamento por carro está associado ao aumento de $6 \%$ no risco à obesidade [9]. No Reino Unido, entre 2009 e 2011, uma pesquisa demostrou que o uso de caminhada ou bicicleta como meio de deslocamento para o trabalho está associado à redução de risco ao desenvolvimento de doenças como diabetes e hipertensão em comparação às pessoas que utilizam transporte individual [16].

Por fim, dados da Organização Mundial de Saúde (WHO) [32] apontam que, 
anualmente, aproximadamente 3,2 milhões de mortes no mundo são atribuídas à prática insuficiente de atividades físicas. Especialistas no mundo inteiro começam a discutir e reconhecer o papel do transporte ativo como alternativa para o sedentarismo e melhoria da qualidade de vida nos ambientes urbanos. É fundamental o trabalho de expansão da rede de corredores amigos para que mais e mais corredores se disponham a utilizar a corrida como mobilidade urbana e assim expandir a rede para outras cidades e estados brasileiros.

\section{REFERÊNCIAS}

[1] ANDERSEN L. B, SCHNOHRP, SCHROLL M, HEIN H. O. Mortality associated with physical activity in leisure time, at work, in sports and cycling to work. Ugeskr Laeger, v.164, n.11, 2002.

[2] ANTP (Associação Nacional dos Transportes Públicos). Mobilidade urbana começa na sua calçada. Disponível em: <http://www.antp.org.br/website/ noticias/show.asp?npgCode=6E90A40D-E935-46F9-A8EA-981113167D81>. Acesso em 9 de jul. 2014.

[3] BARROS, T. Limiar anaeróbico: entenda como atletas alcançam média de 20km/h. Disponível em:<http://globoesporte.globo.com/eu-atleta/saude/ noticia/2013/o2/limiar-anaerobico-entenda-como-atletas-alcancam-media-de-2okmh.html>. Acesso em 19 jun. 2014.

[4] CET (Companhia de Engenharia de Tráfego). Desempenho do Sistema Viário Principal - DSVP 2012. Pesquisa de Monitoração da Fluidez Março de 2013. Disponível em: <http://www.cetsp.com.br/media/228058/2012\%20\%20 volumes\%2oe\%2ovelocidades.pdf $>$. Acesso em 9 jul. 2014.

[5] CORPORE. Evolução de Participantes das corridas organizadas pela Corpore (1994 a 2013). Disponível em: <http://www.corpore.org.br/cor_corpore_estatisticas.asp >. Acesso em 9 jun. 2014.

[6] ESTADÃO. Epidemia triplica o número de mortes por obesidade em dez anos no país. Disponível em: <http://saude.estadao.com.br/noticias/ geral,epidemia-triplica-o-numero-de-mortes-por-obesidade-em-dez-anos-no-pais-imp-,1159484>. Acesso em 9 jul. 2014.

[7] FLORINDO, A. A, SALVADOR, E. P., REIS, R. S., GUIMARÃES, V. V. Percepção do ambiente e prática de atividade física em adultos residentes em região de baixo nível socioeconômico. Rev. Saúde Pública, São Paulo , v.45, n.2, 2011 . Disponível em: <http://www.scielo.br/scielo.php?script=sci arttext\&pid=So034-89102011000200009\&lng=pt\&nrm=iso $>$. Acesso em 9 jul. 2014. DOI: http://dx.doi.org/10.1590/So034-89102011000200009

[8] FLORINDO,A.A, GUIMARÃES, V.V,SALVADOR,E.P., REIS, R.S. Validação de uma escala de percepção do ambiente para a prática de atividade física em adultos de uma região de baixo nível socioeconômico. Rev. Bras. Cineantropometria e Desempenho Humano, v.14, n.6, 2002. Disponível em: <http://www.scielo.br/scielo.php?pid=S1980-00372012000600004\&script $=$ sci_arttext $>$. Acesso 
em 9 jul. 2014. DOI: http://dx.doi.org/10.5007/1980-0037.2012v14n6p647

[9] FRANK, L. D., ANDRESEN, M. A., SCHMID, T. L. Obesity relationships with community design, physical activity, and time spent in cars. American Journal of Preventive Medicine, v.27, n.2, 2004. Disponível em: <http://www. ajpmonline.org/article/So749-3797(04)00o87-X/fulltext>. Acesso em 9 out. 2014. DOI: http://dx.doi.org/10.1016/j.amepre.2004.04.011

[10] GREENPEACE. Fuja do trânsito: corra para o trabalho! Disponível em: <http://www.greenpeace.org/brasil/pt/Blog/fuja-do-trnsito-corra-para-o-trabalho/blog/49473/>. Acesso em 9 out. 2014.

[11] IBGE. Censo Demográfico 2010: Resultado da Amostra - Educação e deslocamento. Disponível em: <http://www.ibge.gov.br/home/estatistica/populacao/censo2010/educacao_e_deslocamento/>. Acesso em 9 out. 2014.

[12] IBGE. Pesquisa Nacional por Amostragem de Domicílios - PNAD. Disponível em: <http://www.ibge.gov.br/home/estatistica/populacao/trabalhoerendimento/pnad2012/default_sintese.shtm > . Acesso em 9 out. 2014.

[13] IGUANA SPORTS. DNA de Corredor. Disponível em: $<$ http://www.iguanasports.com.br/2013/news/pdf/DNACorredor.pdf $>$. Acesso em 9 jul. 2014.

[14] IPEA (Instituto de Pesquisa Econômica Aplicada). Ricos e pobres perdem cada vez mais tempo no trânsito. Disponível em: <http://www.ipea.gov. br/portal/index.php?option $=$ com_content $\& v i e w=\operatorname{article} \& i d=17212>$. Acesso em 9 jul. 2014.

[15] JORNAL CORRIDA. Corrida amiga. Disponível em: <http://www.jornalcorrida.com.br/runbrasil/2014/o6/corrida-amiga/>. Acesso em 9 out. 2014.

[16] LAVERTY, A. A.; MINDELL, J. S; WEBB, E. A.; MILLET,, C. Active Travel to Work and Cardiovascular Risk Factors in the United Kingdom. American Journal of Preventive Medicine, v.45, n.3, 2013. Disponível em: <http:// www.ajpmonline.org/article/So749-3797(13)00333-4/fulltext>. Acesso em 9 jul. 2014. DOI: http://dx.doi.org/10.1016/j.amepre.2013.04.012

[17] LITMAN, T. Active transportation policy issues. Canadá: Victoria, B. C., 2003. Disponível em: <http://www.vtpi.org/act_tran.pdf $>$. Acesso em: jul. 2014.

[18] METRO (Companhia do Metropolitano de São Paulo). Pesquisa de Mobilidade Urbana. Disponível em: <http:// www.metro.sp.gov.br/metro/numeros-pesquisa/pesquisa-mobilidade-urbana-2012.aspx>. Acesso em 9 out. 2014.

[19] MILLETT C, AGRAWAL S, SULLIVAN R, VAZ M, KURPAD A, et al. Associations between Active Travel to Work and Overweight, Hypertension, and Diabetes in India: A Cross-Sectional Study. PLoS Med, v.10, n.6, 2013. Disponível em: <http://www.plosmedicine.org/article/info\%3Adoi\%2F10.1371\%2Fjournal. pmed.1001459>. Acesso em 9 out. 2014.

[20] MINISTÉRIO DA SAÚDE. Portal da Saúde. Disponível em: <http://tabnet. datasus.gov.br/>. Acesso em 9 jul. 2014.

[21] MOBILIZE BRASIL. Calçadas do Brasil - Médias por local avaliado. Disponível em: <http://www.mobilize.org.br/estatisticas/32/notas-calcadas-do-brasil.html>. Acesso em 9 out. 2014. 
[22] MOBILIZE BRASIL. 'Nossas calçadas são verdadeiras ciladas', dizem adeptos da corrida como mobilidade urbana. Disponível em: <http://www. mobilize.org.br/noticias/6511/nossas-calcadas-sao-verdadeiras-ciladas-dizem-adeptos-da-corrida-na-mobilidade-urbana.html>. Acesso em 9 out. 2014.

[23] MOBILIZE BRASIL. Mobilidade urbana começa na sua calçada. Disponível em: <http://www.mobilize.org.br/noticias/6398/mobilidade-urbana-comeca-na-sua-calcada.html>. Acesso em 9 out. 2014.

[24] MORRIS, E; GUERRA, E. Mood and mode: does how we travel affect how we feel? New York: Transportation Journal, 2014. Disponível em: <http://www.urbangateway.org/system/files/documents/urbangateway/mood_and_mode does_how_we_travel_affect_how_we_feel.pdf $>$. Acesso em 9 out. 2014. DOI: 10.1007/s11116-014-9521-x

[25] NEW YORK CITY. Active Design Guidelines: Promoting Physical Activity and Health in Design. Disponível em: <http://centerforactivedesign.org/dl/ guidelines.pdf $>$. Acesso em 9 jul. 2014.

[26] Origem e Destino (OD). Pesquisa de Origem e Destino 2007 - Região Metropolitana de São Paulo. Disponível em: <http://www.nossasaopaulo.org.br/ portal/files/Pesquisa_Origem_Destino_Metro.zip>. Acesso em 9 jul. 2014.

[27] PATE R. R. et al. Physical activity and public health: a recommendation from the Centers for Disease Control and Prevention and the American College of Sports Medicine. JAMA, v.273, n.o, 1995. Disponível em: <http://jama.jamanetwork.com/article.aspx? articleid $=386766>$. Acesso em 9 jul. 2014. DOI: 10.1001/jama.1995.03520290054029

[28] SALDIVA, P. Pobres são os mais atingidos pela poluição urbana, diz médico da USP em entrevista à Carta Maior. Disponível em: <http://www.cartamaior. com.br/?/Editoria/Politica/Pobres-sao-os-mais-atingidos-pela-poluicao-urbana-diz-medico-da-USP/4/25595>. Acesso em 9 jul. 2014.

[29] SALVADOR, E. P.; FLORINDO, A. A.; REIS, R. S.; COSTA, E. F. Percepção do ambiente e prática de atividade física no lazer entre idosos. Rev. Saúde Pública, v.43, n.6, 2009. Disponível em: <http://www.scielo.br/scielo. php?pid=So034-89102009000600008\&script $=$ sci_abstract\&tlng $=$ pt $>$. Acesso em 9 jul. 2014. DOI: http://dx.doi.org/10.1590/So034-89102009005000082

[30] SALVADOR, E. P.; REIS, R. S.; FLORINDO, A. A. A prática de caminhada como forma de deslocamento e sua associação com a percepção do ambiente em idosos. Rev. Bras. de Atividade Física e Saúde, v.14, n.3, 2009b. Disponível em: <http://periodicos.ufpel.edu.br/ojs2/index.php/RBAFS/article/ view/774>. Acesso em 9 jul. 2014.

[31] SÃO PAULO. Substitutivo ao Projeto de Lei No 688/2013. Aprova a Política de Desenvolvimento Urbano e o Plano Diretor Estratégico do Município de São Paulo e revoga a Lei 13.430/2002. Disponível em: <http:// cidadeaberta.org. br/wp-content/uploads/2014/06/MINUTA_SUB2_PDE2013_2014.06.16_final_vf.pdf $>$. Acesso em 9 jul. 2014.

[32] TASSIANO, R. M.; FEITOSA, W. M.; TENORIO, M. C. M. Fatores associados ao deslocamento ativo e indicadores de saúde em trabalhadores da 
indústria. Rev. Bras. de Atividade Física e Saúde, Pelotas, v.18, n.4, jul.2013. Disponível em: <http://periodicos.ufpel.edu.br/ojs2/index.php/RBAFS/ article/viewFile/2688/2669>. Acesso em 9 jul. 2014. DOI: http://dx.doi. org/10.1282o/rbafs.v.18n 4 p 483

[33] WHO (WORLD HEALTH ORGANIZATION). NCD Country Profiles 2011. Disponível em: <http://www.who.int/nmh/countries/bra_en.pdf >. Acesso em 9 jul. 2014.

\section{AGRADECIMENTOS}

Agradecemos todos os participantes do movimento Cidade Ativa e da Corridaamiga. Agradecemos também pelo apoio em nossas campanhas, seja como parceiro de ação e/ou divulgação: Bike Anjo, Mobilize, Cidadera, Sampapé, oGangorra, Grupo de Estudos e Pesquisas Epidemiológicas em Atividade Física e Saúde (GEPAF/EACHUSP), nutricionista Serena Del Favero e educadora física Nathália Zampronha.

SILVIA REGINA STUCH\| CRUZ doutoranda em Política Científica e Tecnológica do Instituto de Geociências da Universidade de Campinas (DPCT-Unicamp) - silviacruz@ige.unicamp.br

ANNA GABRIELA HOVERTER CALLEJAS mestre em desenho urbano pela Graduate School of Architecture, Planning and Preservation da Columbia University

MARIANA SANTOS pós-graduanda em Planejamento e Gestão de Cidades pelo Programa de Educação Continuada da Escola Politécnica da Universidade de São Paulo 